\section{New insertion site for Nexplanon insertion}

In October 2018, Merck Sharp and Dohme (MSD) changed the advised area of the arm where Nexplanon should be inserted. They are doing this because of the very rare but serious complication of cardiovascular insertions. During the past 18 months, they have been discussing with anatomists and others where is the best place to insert Nexplanon that avoids this complication. After this long discussion period, they have decided on 3-5 cms away from the biceps/triceps sulcus over triceps. This decision was relayed at the Annual Expert Remover Meeting in late 2018 without involving this group of experienced impalpable implant practitioners for their thoughts. To insert in this position, they are advising the arm will need to be rotated back with the hand behind the patients head so that the arm will be on the couch. The implant insertion is far away from the sulcus over the triceps as the ulnar nerve lies very superficial in the triceps as insertions over the triceps nearer the sulcus could cause ulnar nerve complications as have been reported.

Theoretically, this is a safe area but in my opinion the practical implications of this site for removal of Nexplanon and especially impalpable implants have not been considered.

Over the past 14 years, I have removed many hundreds of impalpable implants from subcutaneous tissue, below fascia and from muscle and implants from alongside the ulnar nerve and vascular structures. Very few of those were yellow carded. The majority have been over biceps, sulcus or over triceps within 1-2 cms of the sulcus. To remove them, I have the arm extended on a trolley and with this flat area I scan mark the arm, and then using an open technique it is a straightforward procedure to find and remove the implant. The other technique used to remove implants is called the needle lift technique and with the arm in this position is also straightforward. Patient comfort, accessibility, light source, assistant position and instruments positioning are uncomplicated with the arm in this position.

To operate and remove impalpable implants in this new area of the arm, and there will be as many cases, will be difficult. I have been involved with five such cases but if this area is to be the only area, then it will be the norm. I rotated the arm trying a variety of positions but it was a compromise of patient comfort versus accessibility. Scanning is possible but removal is not as easy. The light source is difficult to arrange, the instruments especially the tissueholding forceps are restricted by the couch. The assistant can see very little because of the position of the opening of the skin. Due to my long experience, I did remove these implants. I have since been contacted by other experienced removers who also find it problematic. The needle lift technique will also be compromised as the needle will be advanced towards the ulnar nerve territory.

I feel if this position for insertion is to be the bible I envisage more women being referred to the Surgeons for General Anaesthetics. This will have a cost implication towards the already overstretched National Health Service.

At the same meeting, the anatomy and scanning technique was revised by a radiologist. An area over biceps, away from the sulcus, was stated to be a safe area for insertion of implants. This is the area that the Faculty of Sexual \& Reproductive Healthcare of the Royal College of Obstetrics \& Gynaecologsists (FSRH) Health recommend at present. I totally support this as the area but it will be difficult for the faculty if the new Summaries of product Characteristics (SPC) recommends this new position on the medial aspect of the arm. For those of you in doubt mark an area on your arm where the new implant is to be inserted then envisage removing an implant in this area from muscle.

As an experienced trainer, I feel a revision of the insertion technique so that impalpable implants would be less in number is really what is required.

\section{Martyn R Walling \\ Sidlings Medical Practice, Boston, UK}

Correspondence to Dr Martyn R Walling, Sidlings Medical Practice, Boston, UK; martyn.belmontdoc@sky. com

Funding The authors have not declared a specific grant for this research from any funding agency in the public, commercial or not-for-profit sectors.

Competing interests None declared.

Patient consent for publication Not required.
Provenance and peer review Not commissioned; internally peer reviewed.

(c) Author(s) (or their employer(s)) 2020. No commercial re-use. See rights and permissions. Published by BMJ.

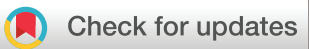

Published Online First 3 October 2019

BMJ Sex Reprod Health 2020;46:82.

doi:10.1136/bmjsrh-2018-200279

\section{ORCID iD}

Martyn R Walling http://orcid.org/00000001-8187-9560 